\title{
Epidemiologic Studies of Travelers' Diarrhea, Severe Gastrointestinal Infections, and Cholera
}

Robert Steffen
From the Institute for Social and Preventive Medicine, University of Zurich, Zurich, Switzerland

A retrospective survey, which is based on interviews conducted between 1975 and 1984 with 20,000 European tourists returning from 15 destinations in various climatic zones, demonstrates that travelers' diarrhea is the most frequent health problem encountered by travelers in the tropics. The incidence varied from $4 \%$ to $51 \%$, depending on the destination. High-risk groups were persons younger than 30 years, adventurous travelers, and travelers with preexisting gastrointestinal illnesses. Illness acquired at various geographic regions showed only minor differences in chronology and symptomatology. The clinical course of travelers' diarrhea was usually short and mild. Additionally, by longitudinal and retrospective analyses, the incidence and prognosis of gastrointestinal infections of greater severity that were acquired after a short stay in a developing country, such as giardiasis, amebiasis, typhoid fever, and cholera, were evaluated; typhoid fever and cholera, in particular, were found to be quite rare.

\section{Travelers' Diarrhea}

Travelers' diarrhea is the most frequent health problem among visitors to developing countries. We base this statement on studies that we performed between 1975 and 1984 of 17,866 European tourists who stayed in various countries in the tropics and subtropics and of a control group of 1,379 visitors to the United States and Canada. We carried out these studies because previous ones had not surveyed the most frequent travelers to developing countries - vacationers - and because no worldwide data were available.

For this survey, most of the data were collected with the assistance of cabin crews who distributed and collected questionnaires during charter flights returning to Switzerland and Germany. The remaining data were obtained from motorists returning from southern Europe who obtained their questionnaires while waiting at the customs checkpoint of Chiasso, Switzerland, at the Italian-Swiss border. Details on the methods used have previously been reported [1]. The average response rate for air travelers was $64 \%$; once bilingual questionnaires were used, $82 \%$ of all such travelers provided valuable data.

The proportion of men among the travelers surveyed ranged from $40 \%$ for travelers returning from the beach resorts of the Mediterranean, to $75 \%$ for those returning from Thailand. The mean age of all

\footnotetext{
Please address requests for reprints to Dr, Robert Steffen, Institute for Social and Preventive Medicine, University of Zurich, Sumatrastrasse 30, CH 8006 Zurich, Switzerland.
}

travelers was 40 years; the age distribution is depicted in table 1. The mean length of stay in the various climatic zones was two to three weeks. The proportion of travelers who were vacationers exceeded $80 \%$ at each destination, a figure that correctly reflects the fact that tourists are the most frequent visitors to the developing world.

The magnitude of the problem of diarrhea in travelers becomes obvious with inspection of figure 1 ; in terms of incidence it is by far the predominant health problem for those visiting the tropics. More than $30 \%$ of the tourists were affected by travelers' diarrhea, which we defined-similarly to Merson et al. [2] and Sack et al. [3] - as the occurrence of three or more unformed stools per day or as any number of such bowel movements, when accompanied by fever, abdominal cramps, or vomiting. An additional $3 \%$ of the travelers reported loose stools, i.e., one to two watery or unformed bowel movements in the absence of any of the aforementioned accompanying symptoms. For the purpose of this report, the term diarrhea will be used to mean the sum of travelers' diarrhea and loose stools.

The incidence of diarrhea for a stay of exactly two weeks varied significantly according to the geographic region visited (figure 2). Low rates were observed in visitors to the United States and Canada, southern Europe, the Canary Islands, and the $\mathrm{Ca}$ ribbean with the exception of Haiti. The attack rate was highest for visitors to the Tunisian region of Monastir $-56 \%$ - followed by Togo, with $53 \%$. It is of interest that within Tunisia, the incidence var- 
Table 1. Characteristics and symptoms of 19,245 travelers surveyed for travelers' diarrhea (entire stay abroad).

\begin{tabular}{|c|c|c|c|c|c|c|c|c|c|}
\hline \multirow[b]{2}{*}{ Criteria } & \multirow[b]{2}{*}{$\begin{array}{l}\text { No. of } \\
\text { travelers }\end{array}$} & \multirow{2}{*}{$\begin{array}{c}\text { No. of cases } \\
\text { of travelers' } \\
\text { diarrhea }\end{array}$} & \multicolumn{2}{|c|}{ Incidence $(\%)$} & \multicolumn{5}{|c|}{$\begin{array}{l}\text { Percentage of affected patients } \\
\text { with concomitant symptoms }\end{array}$} \\
\hline & & & $\begin{array}{l}\text { Travelers' } \\
\text { diarrhea }\end{array}$ & $\begin{array}{l}\text { Loose } \\
\text { stools }\end{array}$ & $\begin{array}{l}\text { Abdominal } \\
\text { cramps }\end{array}$ & $\begin{array}{l}\text { Vomit- } \\
\text { ing }\end{array}$ & Fever & $\begin{array}{c}\text { Blood } \\
\text { in stool }\end{array}$ & $\begin{array}{l}\text { Mucus } \\
\text { in stool }\end{array}$ \\
\hline \multicolumn{10}{|l|}{ Destination } \\
\hline \multicolumn{10}{|l|}{ Tropics $(n=10,852)$} \\
\hline East Africa & 2,646 & 797 & 30.1 & 3.6 & 47 & 12 & 11 & 13 & 16 \\
\hline West Africa & 802 & 317 & 39.5 & 3.4 & 52 & 15 & 9 & 15 & 27 \\
\hline Sri Lanka/Maldives & 1,371 & 477 & 34.8 & 3.4 & 59 & 13 & 9 & 15 & 18 \\
\hline Thailand & 1,838 & 409 & 22.3 & 2.6 & 48 & 14 & 12 & 13 & 20 \\
\hline Far East & 2,470 & 775 & 31.4 & 3.8 & 53 & 14 & 12 & 16 & 23 \\
\hline Brazil & 1,305 & 431 & 33.0 & 2.6 & 55 & 13 & 12 & 18 & 21 \\
\hline South America & 420 & 152 & 36.2 & 4.0 & 63 & 15 & 13 & 12 & 18 \\
\hline \multicolumn{10}{|l|}{ Subtropics $(n=6,880)$} \\
\hline Tunisia & 2,214 & 1,111 & 50.2 & 6.0 & 72 & 12 & 13 & $\mathrm{NA}^{*}$ & NA \\
\hline Canary Islands & 1,006 & 203 & 20.2 & 3.5 & 51 & 12 & 7 & NA & NA \\
\hline Rhodes & 987 & 126 & 12.8 & 3.3 & 57 & 17 & 8 & NA & NA \\
\hline \multicolumn{10}{|c|}{ Southern Europe (Italy, France, } \\
\hline Greece, etc.) & 720 & 109 & 15.1 & 2.9 & 55 & 14 & 6 & NA & NA \\
\hline Caribbean & 849 & 168 & 19.8 & 3.4 & 63 & 13 & 6 & NA & NA \\
\hline Mexico & 1,104 & 342 & 31.0 & 3.6 & 63 & 18 & 15 & NA & NA \\
\hline United States and Canada ${ }^{\dagger}$ & 1,379 & 71 & 5.1 & 0.7 & 51 & 21 & 20 & 41 & 27 \\
\hline More than one region & 134 & 35 & 26.1 & 5.2 & 50 & 10 & 7 & 14 & 17 \\
\hline \multicolumn{10}{|l|}{$\operatorname{Sex} \ddagger$} \\
\hline Male & 6,223 & 1,900 & 30.5 & 4.0 & 45 & 10 & 11 & 14 & 19 \\
\hline Female & 4,268 & 1,355 & 31.7 & 2.3 & 62 & 17 & 10 & 17 & 23 \\
\hline \multicolumn{10}{|l|}{ Age (years) $\ddagger$} \\
\hline$\leqslant 19$ & 177 & 53 & 29.9 & 5.6 & 45 & 10 & 11 & 8 & 15 \\
\hline $20-29$ & 2,795 & 1,023 & 36.6 & 3.4 & 56 & 13 & 11 & 16 & 21 \\
\hline $30-39$ & 2,911 & 905 & 31.1 & 3.7 & 55 & 13 & 11 & 15 & 21 \\
\hline $40-49$ & 1,858 & 501 & 27.0 & 2.9 & 55 & 13 & 12 & 14 & 21 \\
\hline $50-59$ & 1,641 & 464 & 28.3 & 2.3 & 49 & 14 & 13 & 12 & 20 \\
\hline $60-69$ & 974 & 250 & 25.7 & 3.6 & 36 & 10 & 7 & 15 & 17 \\
\hline$\geqslant 70$ & 232 & 53 & 22.8 & 5.6 & 18 & 7 & 10 & 11 & 12 \\
\hline \multicolumn{10}{|l|}{ Previous travel in tropics } \\
\hline Yes & 5,851 & 1,701 & 29.1 & 3.0 & 51 & 13 & 12 & 15 & 19 \\
\hline None & 4,426 & 1.431 & 32.3 & 3.8 & 52 & 13 & 10 & 15 & 21 \\
\hline \multicolumn{10}{|l|}{ Travel characteristics $\ddagger$} \\
\hline Beach vacation & 935 & 261 & 27.9 & 2.8 & 52 & 13 & 12 & 13 & 20 \\
\hline Tour in group & 3,299 & 1,009 & 30.6 & 3.8 & 50 & 12 & 9 & 14 & 18 \\
\hline Individual tour & 3,922 & 1,253 & 31.9 & 3.1 & 53 & 14 & 12 & 16 & 21 \\
\hline Adventure tour & 522 & 178 & 34.1 & 2.7 & 58 & 14 & 15 & 17 & 25 \\
\hline
\end{tabular}

* NA = not assessed; a shorter questionnaire was used on shorter flights and for interviews on customs posts.

$\dagger$ Control group.

$\ddagger$ Tropics only.

ied from $26 \%$ to $89 \%$ in 21 hotels, each of which was visited in 1980 by more than 20 persons in the study; we interpret this finding as a significant reflection of hygienic conditions. Four-star hotels were not necessarily those whose visitors had the lowest incidence of travelers' diarrhea, e.g., two establishments belonging to an international French chain were grouped in the list of the top one-third of the hotels according to incidence of traveler's diarrhea. In 1981, with the assistance of the Tunisian authorities, the management personnel for each of the 21 hotels were informed about hygienic measures recommended by the World Health Organization [4] and were requested to take appropriate steps to remedy prob- 


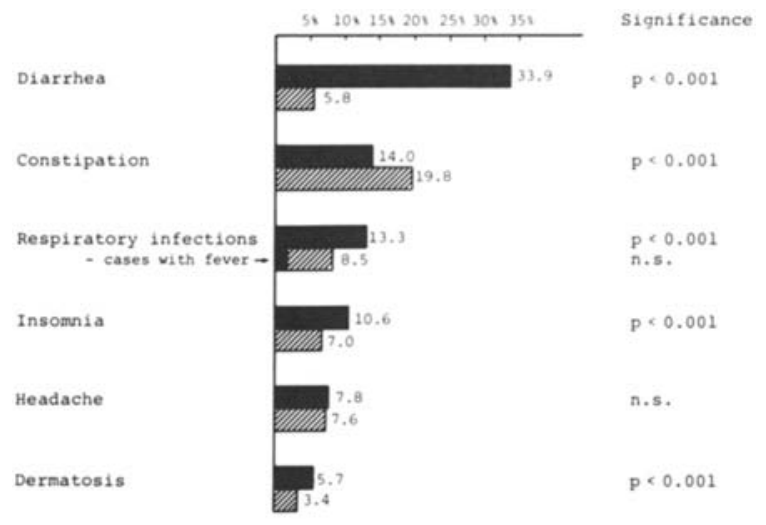

Figure 1. Incidence of health problems during a short stay in the tropics $(n=17,866)(\square)$ or the United States or Canada $(n=1,379)(\mathbb{Z})$ n.s. = not significant.

lems. The effect of this action was determined by an additional inquiry in 1982 (figure 3). With the exception of the hotel that had had the highest incidence of diarrhea among its guests, no improvement in the incidence could be demonstrated. The travel organizations had meanwhile stopped doing business with 15 of the hotels. In contrast, on the Canary Islands or on Rhodes, the only other resort areas where the visitors had stayed at the same hotel long enough for our investigation, no evident difference between individual hotels could be detected.

As primarily suggested by DuPont [5], we can distinguish three grades of risk for travelers' diarrhea if we assume that the travelers concerned are residents of a highly industrialized country and that their stays abroad do not exceed one month. Low risk usually does not exceed $8 \%$, as in travelers to the United
States, Canada, northern and central Europe, Australia, and New Zealand. Intermediate risk is found for travelers to most islands of the Caribbean, the major resorts on the northern Mediterranean and in the Pacific, and, on the basis of limited data in our study, presumably Israel, Japan, and South Africa. High risk, with incidence rates of $20 \%-56 \%$, is found for travelers to the developing countries in Africa, Asia, and Latin America.

Host factors may also play a role in the risk of acquiring travelers' diarrhea (table 1). There are definite differences between the age groups, 20-29-yearold adults being most often affected $(P<.0001)$. Although the young adults had a more adventurous travel style and more of the older adults had previous experience in the tropics, these findings were not the only causes of the age difference in incidence. As formerly observed by Kean [6] in travelers to Mexico, the explanation for this finding may be that younger travelers have larger appetites and therefore consume greater numbers of pathogenic agents.

On the other hand, the incidence of travelers' diarrhea does not vary significantly in men and women $(P=.3)$. Persons with previous experience traveling in developing countries did not enjoy a greatly reduced incidence, though a statistically significant difference was detected $(P=.0004)$ (table 1). However, we did not separately assess the small minority in this tourist population who had visited the same destination a few months before. The attack rate was slightly elevated $(P=.035)$ among travelers more "on the go" after reaching the destination and among those whose travel style was individualistic and adventurous. Adventurous travelers were defined here

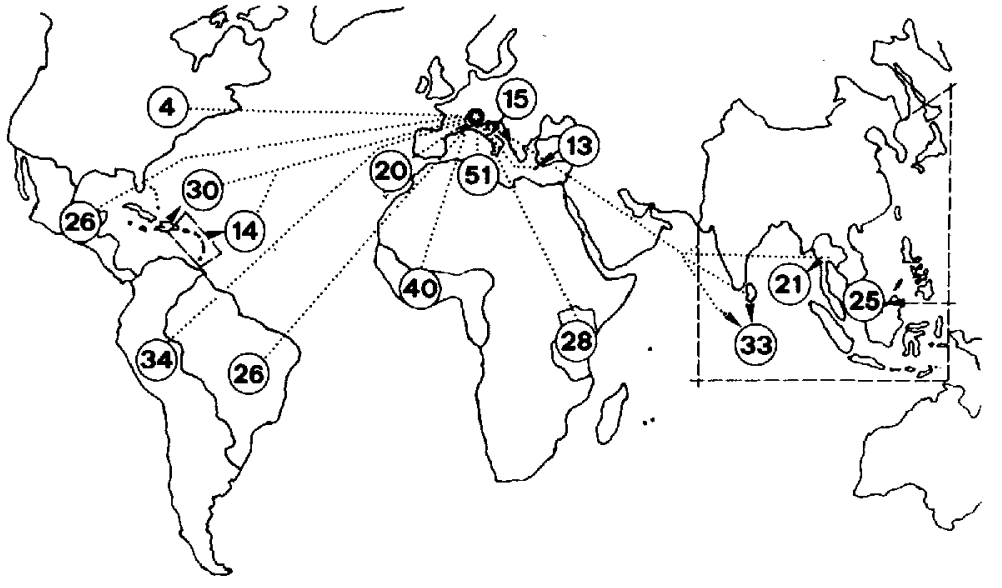

Figure 2. Incidence $(\%)$ of travelers' diarrhea among 17,280 tourists during a stay of 14 days at various locations. Travelers who stayed $\leqslant 13$ days and those who manifesed diarrhea after the 14 th day were excluded. 


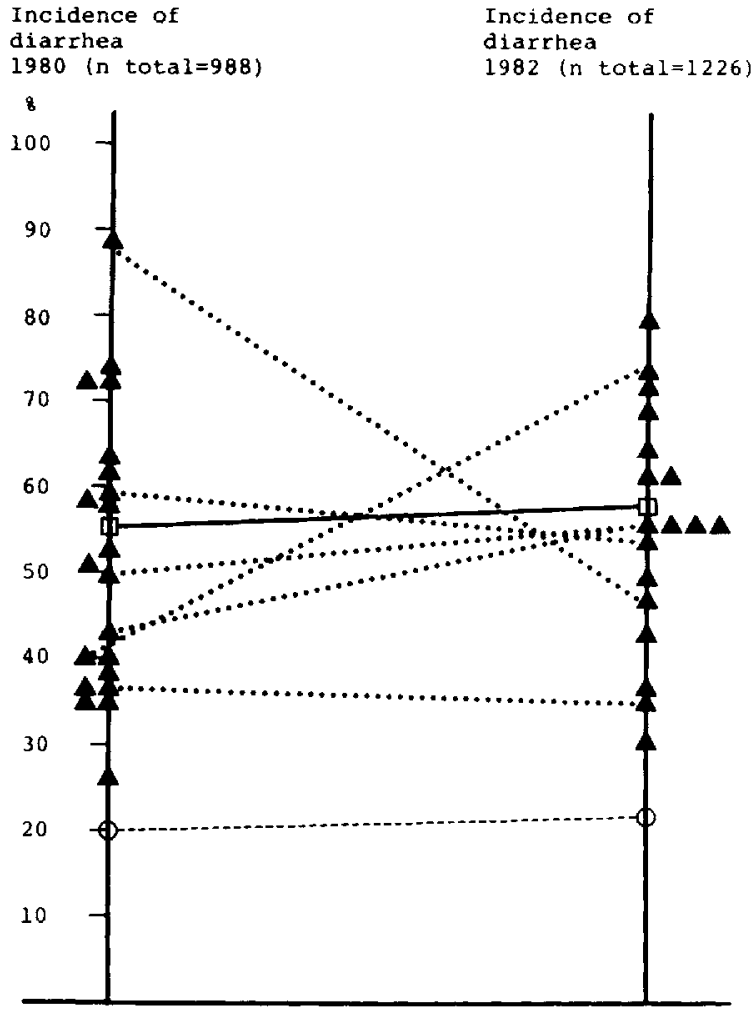

Figure 3. Incidence of diarrhea among guests of 21 different hotels $(\boldsymbol{\Delta})$ in Tunisia, each of which was visited by $\geqslant 20$ travelers in 1980 and $1982 ;(\square \square \square)=$ mean incidences for all 21 hotels, and $(\mathrm{O}-\mathrm{O})=$ mean incidences for hotels in the Canary Islands (control).

as those who stayed in private homes with the native population, in camps, in inexpensive hotels, or in other such lodgings.

It should be emphasized that the incidence rates presented here under- rather than overestimate the occurrence of travelers' diarrhea. In longitudinal studies in which a record of episodes of diarrhea was kept in a diary [7], we had observed somewhat higher rates. In the present study, some of the tourists who had suffered from mild attacks apparently forgot about their ailment until the retrospective investigation took place a few days later, but these cases were obviously of little medical relevance. Also, an unfortunate trend is to be noted. For all destinations that we investigated with use of two or more identical questionnaires at intervals of one to five years, travelers' diarrhea increased in incidence by $1 \%$ to $5 \%$; nowhere did we find a decrease in incidence.

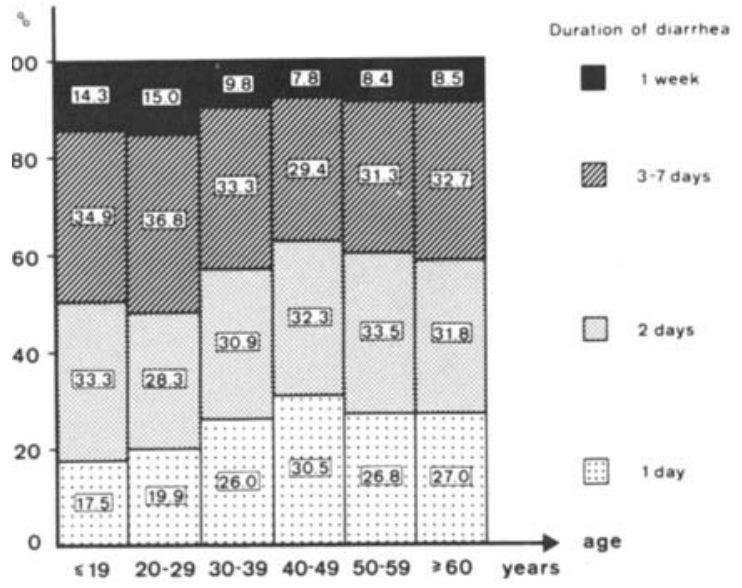

Figure 4. Proportion of 3,339 travelers in the tropics in six age groups with travelers' diarrhea of various durations.

\section{Chronology}

Diarrhea in travelers usually starts within the first days of the stay abroad [1]. In our study, each investigated region, including North America, showed the highest proportion of onsets on the third day. The time of onset for subgroups of travelers with symptoms such as fever, vomiting, abdominal cramps, of blood or mucus in the stools, or those who had only loose stools did not significantly differ from that for travelers without such manifestations.

The duration of travelers' diarrhea is usually short, particularly in areas of low incidence [1]. In the present study, the symptoms vanished within $24 \mathrm{hr}$ in $20 \%$ of those affected and within two days in $55 \%$. Ten percent of those affected, however, were bothered for longer than a week. In the tropics, the mean duration of diarrhea was 3.6 days. When accompanying signs such as abdominal cramps, vomiting, fever, and blood or mucus in the stools were absent, the mean duration was 3.2 days; when such additional symptoms were present, the duration averaged about four days. The majority of our patients attempted to treat diarrhea with some medication. However, for the 918 patients with cases acquired in tropical regions who abstained from any treatment, the mean duration was only marginally longer -4.1 days. Whether this latter population had milder cases remains a question.

Patients $\leqslant 29$ years old with diarrhea were inconvenienced for a longer period (figure 4). This age difference $(P<.0001)$ was not due to differences ei. ther in the extent of experience in the tropics or in 


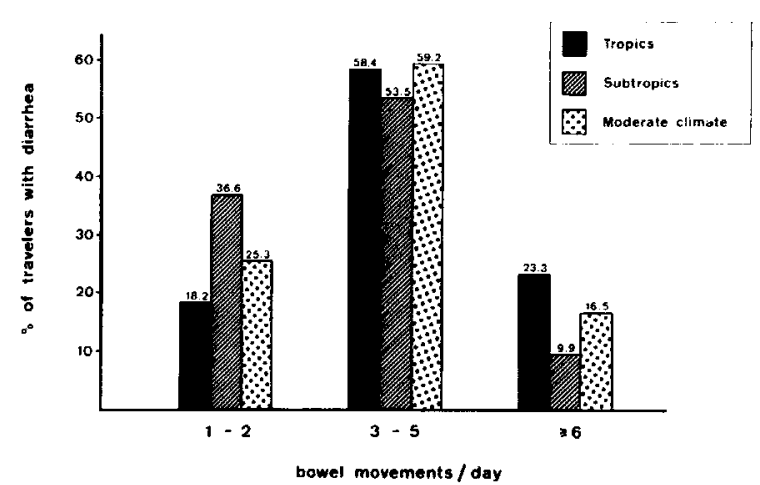

Figure 5. Maximal daily frequency of bowel movements for 16,568 travelers in various climatic regions. Reprinted with permission from the Scandinavian Journal of Gastroenterology [8].

travel style or to a general tendency among the younger travelers to exaggerate but rather, as previously postulated, to the greater amount of enteropathogencontaining food consumed by such travelers. The question of whether the significantly $(P<.001)$ shorter duration of cases that started later in the course of the stay abroad [1] is due to some improved defense mechanism is a reasonable one, but it cannot be answered by the present study, which is strictly epidemiologic in nature.

\section{Symptomatology}

The attacks of diarrhea recorded in the present study usually took a mild course. More than $25 \%$ of the cases did not fulfill the classic criteria of an increase in the number of stools (figure 5); travelers with such cases reported only one to two bowel movements. Far fewer patients reported loose stools, as many of such patients also reported concomitant symptoms. Even in the tropics, $76.7 \%$ of the patients did not suffer from more than five bowel movements per day. Only $72 \%$ of all patients with diarrhea described stools as watery; the remaining patients described stools as unformed.

In almost all regions $>50 \%$ of the patients reported having suffered from abdominal cramps, $\sim 20 \%$ had observed mucus in their stools, and $\sim 15 \%$ had observed blood admixed to the stools. The mean rate of fever and vomiting was slightly less than $15 \%$ (table 1). Women noted abdominal cramps and vomiting significantly more often than did men; cases with fever were slightly more frequent in those with an adventurous travel style. All these symptoms

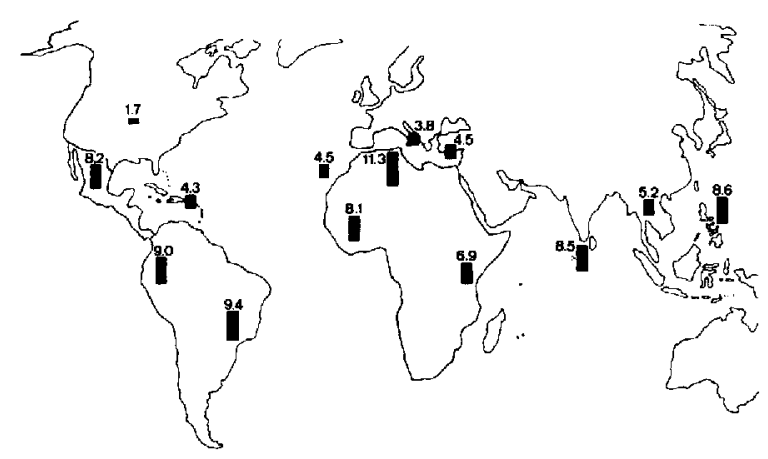

Figure 6. Incidence ( $\%$ ) of dysentery (diarrhea with fever or blood admixed to bowel movements) in 17,280 travelers during a stay of two weeks abroad in various destinations.

appeared to be more frequent in travelers whose destinations were associated with a high incidence of diarrhea. The incidence of dysenteric cases with either fever or blood observed in the bowel movements varied from a high of $11 \%$ in Tunisia to a low of $5 \%$ in the Far East (figure 6). It was even lower in the low- and the moderate-risk areas.

The severe cases of diarrhea with many daily bowel movements did not last longer than the mild ones (figure 7). On the other hand, the longer-lasting ailment was not excessively severe. Therefore, we were not able to identify varieties of diarrhea, e.g., a short

Maximal number of bowel movements/day

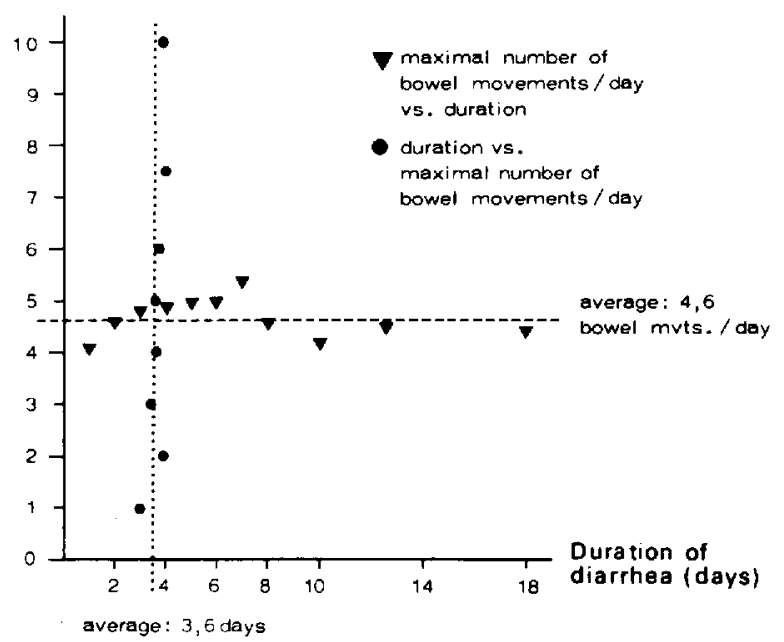

Figure 7. Correlation of severity and duration of diarrhea for 10,555 travelers in the tropics. Reprinted with permission from the Scandanavian Journal of Gastroenterology [8]. 
Table 2. Host factors that contribute to severity of travelers' diarrhea.

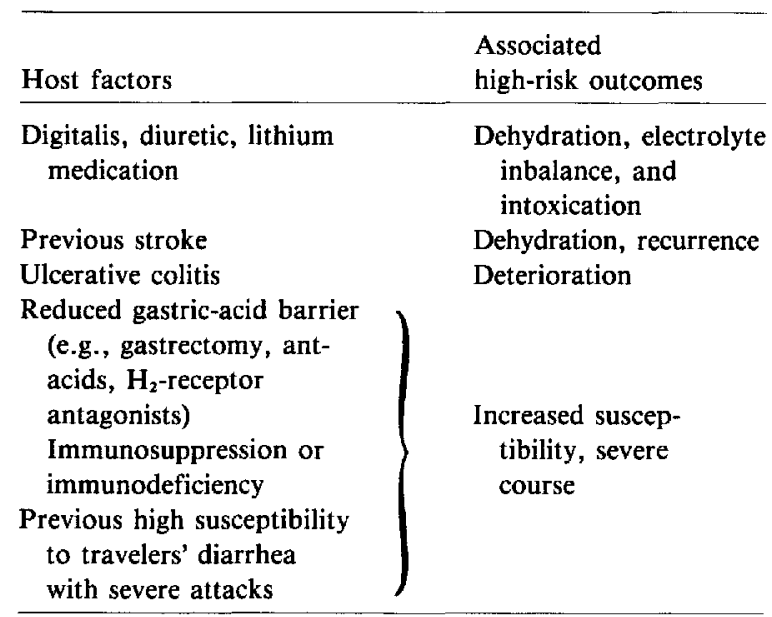

but violent type as opposed to a mild but long-lasting one.

\section{Consequences}

Of the European patients who had been affected by diarrhea in the tropics, only $4 \%$ consulted a local doctor, $1 \%$ requested advice from a physician who by chance was among the group, and $<1 \%$ were admitted to a local hospital.

To analyze severe cases we investigated reports that had been made to travel insurance companies. There were no reports of deaths due to diarrhea for several hundred thousand insured travelers, but in exceptional instances patients had to either postpone their scheduled flight home or be evacuated by air ambulance. From anecdotal experience, we have learned that in such cases concomitant host factors, which are listed on table 2 , often played a role.
We have also observed that patients with preexisting gastrointestinal disorders had a greater likelihood of suffering from gastrointestinal disturbances while abroad, whereas the condition of patients with other groups of diseases was often improved [9] (figure 8). Although caution is warranted concerning the accuracy of self-described diagnoses of patients, it seems reasonable to conclude that persons with preexisting digestive disorders need careful counseling when considering a trip to a high-risk area.

\section{Nutritional Prophylaxis}

The vast majority, i.e., $>90 \%$ of the European travelers whom we surveyed, were well informed about the basic rules of nutritional prophylaxis, which are summarized in the slogan "boil it, cook it, peel it, or forget it." In our retrospective survey, as in many surveys by others, it appeared as if diarrhea occurred more frequently the more one tried to elude it. Already well aware that this observation might reflect a bias on the part of the observers, we postulated that this might be due to differences in recall, and we suggested that the question of differences in the foods eaten by travelers be reassessed in a prospective study [1]. Since then, 688 of 2,240 charter flight tourists to Africa or Asia participated in our longitudinal survey [7] that investigated the influence of the consumption of various food and beverage items on the incidence of travelers' diarhea. Given the low response rate of $30 \%$, the sample of tourists who responded may not be sufficiently representative, but the two most relevant results, which contradict the older retrospective studies, are biologically plausible. Within the first three days abroad, $98 \%$ of the travelers consumed food and/or beverages whose avoidance is traditionally recommended,
Figure 8. Influence of a stay in the tropics on the manifestations of various groups of preexisting diseases in 10,929 travelers. The percentages of travelers reporting improvement and aggravation of disease are indicated by the percentages above and below the midline, respectively.

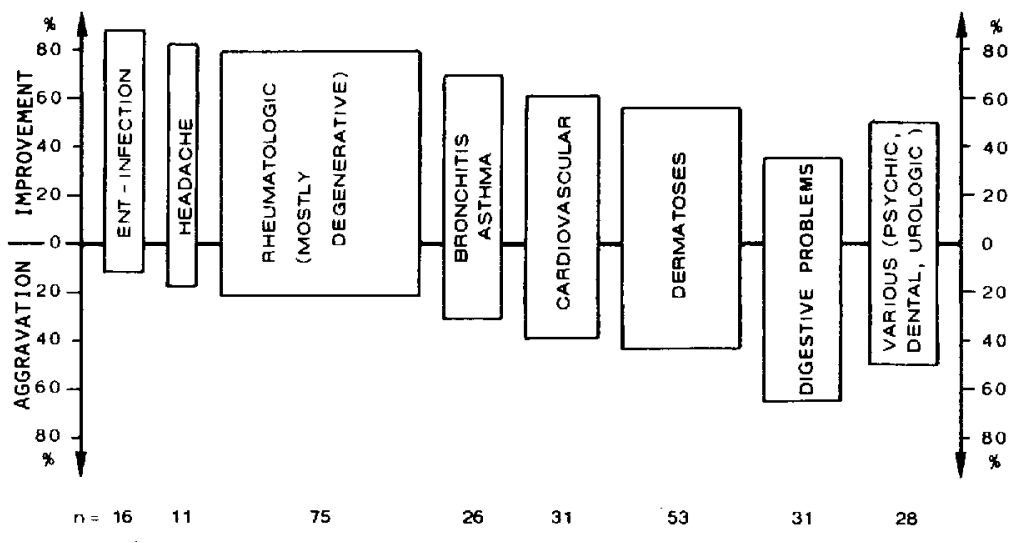


e.g., $71 \%$ ate salads and/or uncooked vegetables, $70 \%$ ate fruit that could not be peeled, and $53 \%$ accepted ice cubes. The incidence of diarrhea was proportional to the number of dietary mistakes committed. Blaser [10] has reviewed these findings in detail.

\section{Other Illnesses}

\section{Severe Gastrointestinal Infections}

In addition to the epidemiologic survey of travelers' diarrhea, we specifically investigated severe gastrointestinal infections that require special attention for diagnosis and therapy. In a recent longitudinal study [11], which has not yet been published in detail, travelers scheduled for stays in the tropics for up to three months were recruited either during outbound charter flights or in the departure lounges prior to boarding of regularly scheduled flights. Overland travelers were recruited at our vaccination center before their departure. Seven months later, i.e., four to six months after the travelers' return from tropical destinations, $73.8 \%$ of the 10,524 recruited travelers had answered a detailed questionnaire about severe imported illnesses.

Of these travelers, $93 \%$ were vacationers (mean age, 40 years). The average duration of stay abroad was 2.8 weeks. Six cases of giardiasis and four cases of ambebiasis per 1,000 travelers per month of stay abroad were certified and treated. The incidence for confirmed salmonellosis was 1 per 1,000 travelers per month and for shigellosis, 0.2 per 1,000 travelers per month, findings that are similar to those of a published retrospective survey [12]. However, in these self-limited infections the true incidence would certainly have been higher. No cases of typhoid fever or cholera were identified. These dangerous infections are rare and can best be investigated in retrospective studies.

To ascertain the risk of typhoid fever we reviewed the 227 cases imported into Switzerland from 1974 through 1981 [13]. In Switzerland virtually all symptomatic cases of diagnosed typhoid fever are reported because of a double notification system by which reporting is compulsory for the patient's doctor and for the microbiologic laboratory. Access to data regarding such cases and regarding the number of residents who have visited countries abroad permits the estimation of the incidence of clinical typhoid fever per journey. The patients with these 227 cases had an average stay of six days for those traveling to $\mathrm{Eu}$ - ropean destinations and of 10 days for overseas destinations. Since Switzerland had hardly any immigrants from outside Europe in these years, the residents who were included in the survey were almost exclusively Swiss nationals. Only a small minority of the travelers to the tropics, $\sim 10 \%$, had obtained parenteral immunization against typhoid. Thirty-five percent of the travelers had taken an ineffective oral vaccine that consisted of killed organisms; the new live oral typhoid vaccine, Ty 2la, had not yet been introduced.

The mean incidence of typhoid per visit to any developing country was estimated to be 1 per 25,000 . The risk of typhoid was lower in southern Europe, where 1 per 200,000 visitors were afflicted; in France the risk was 1 per 1.5 million. Travelers who had come into close contact with persons in the countries visited such as hikers, foreign-aid volunteers, and foreign workers returning to their Swiss posts from locations in southern Europe (mainly Italy and Spain) where they had visited their families were far more often affected than the usual tourists. None of the 227 investigated patients died. These results have since been confirmed by Taylor [14], who assessed 561 cases reported in the United States, more than one-half of which occurred in travelers who had returned after a stay in Mexico. The higher incidence of typhoid documented in a recent British study [15] may be explained by the fact that a substantial proportion of residents surveyed had visited their families who were still living in the developing world, mainly India (table 3 ).

\section{Cholera}

Two studies have recently investigated the problem of cholera in travelers. Snyder [16] reviewed 10 cases imported into the United States between 1962 and 1980, and we analyzed 129 cases imported into Europe or North America between 1975 and 1981 [17]. Both studies estimated that the incidence of cholera is 1 per 500,000 per journey to an endemic area. Obviously, cases in visitors who were successfully treated in the endemic areas escaped detection, but these cases appear to be rare. Also, cases that were successfully treated in the absence of microbiologic diagnosis and cases of mild or asymptomatic infections that remain undetected were not included in these two surveys. Such cases appear to be infrequent and furthermore not very relevant, as shown by our finding [17] that there were only three cases of secondary infections traceable to any of the 129 patients 
Table 3. Frequency of typhoid fever imported from abroad.

\begin{tabular}{|c|c|c|c|}
\hline \multirow[b]{2}{*}{$\begin{array}{l}\text { Region } \\
\text { visited }\end{array}$} & \multicolumn{3}{|c|}{$\begin{array}{l}\text { Frequency/no. of journeys for } \\
\text { residents in indicated countries }\end{array}$} \\
\hline & $\begin{array}{l}\text { Switzerland } \\
1974-1981^{*}\end{array}$ & $\begin{array}{c}\text { United States } \\
1977-1979^{\dagger}\end{array}$ & $\begin{array}{l}\text { United Kingdom } \\
\text { 1978-1982 }\end{array}$ \\
\hline \multicolumn{4}{|l|}{ Northern } \\
\hline Europe & $1 / 6,000,000$ & $1 / 5,000,000$ & Unknown \\
\hline \multicolumn{4}{|l|}{ Southern } \\
\hline Europe & $1 / 200,000^{\S}$ & $1 / 400,000$ & $1 / 300,000$ \\
\hline \multicolumn{4}{|l|}{ Developing } \\
\hline country & $1 / 25,000 \|$ & $1 / 40,000$ & $1 / 3,500 \S$ \\
\hline Mortality & $0 \%$ & $0.2 \%$ & Unknown \\
\hline \multicolumn{4}{|c|}{ 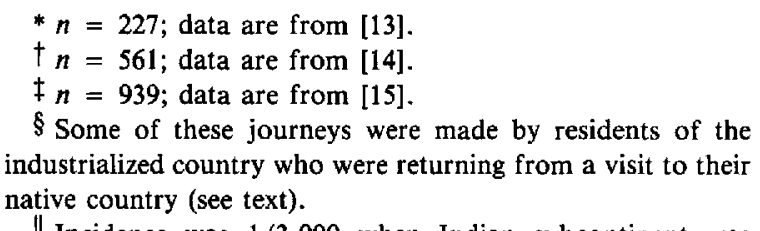 } \\
\hline $\begin{array}{r}\| \text { Incidenc } \\
\text { visited [15a] }\end{array}$ & was $1 / 3,000$ & when Indian & subcontinent was \\
\hline
\end{tabular}

surveyed; in all three cases close contact with one of the patients had occurred.

In our study [17] three groups of travelers importing cholera were detected; $44 \%$ were citizens of industrialized nations, most of whom had stayed abroad for a few weeks only. The majority of patients were citizens of endemic areas: $38 \%$ were foreign workers residing in an industrialized nation who returned after home-leave in their native country, and the remaining $19 \%$ were immigrants, refugees, or tourists who were citizens of countries with endemic areas. Surprisingly, more than one-half of the patients had exported their infection from North Africa, although Morocco and Tunisia had not notified the World Health Organization that endemic cholera had been detected within the surveyed period; neither had Turkey (figure 9).

Several of the patients detected had been administered one or two doses of vaccine before their journey. The rate of immunization among travelers to the endemic areas is known from our own unpublished data (R. Steffen, F. van der Linde, and M. E. Meyer) to have varied between $1 \%$ among travelers to North Africa to $87 \%$ among travelers to the Far East. Only $80 \%$ of the patients were hospitalized, usually for less than one week and never for longer than three weeks. Only two of the patients died, both very shortly after hospital admission.

\section{Conclusions}

Overall, on the basis of surveys of the incidence of diarrhea, severe gastrointestinal infections, typhoid, and cholera in travelers, we conclude the following. (I) Diarrhea is still the most frequent ailment in visitors to the developing world. (2) Travelers' diarrhea usually takes a short and mild course but nevertheless may ruin a substantial part of a stay abroad. Only very exceptionally, because of specific host factors or infections caused by dangerous pathogens, does travelers' diarrhea become life-threatening. (3)
Figure 9. Information regarding the 129 known cases of cholera imported to Europe or North America from 1974 through 1981. Reprinted with permission from the Scandinavian Journal of Gastroenterology [8].

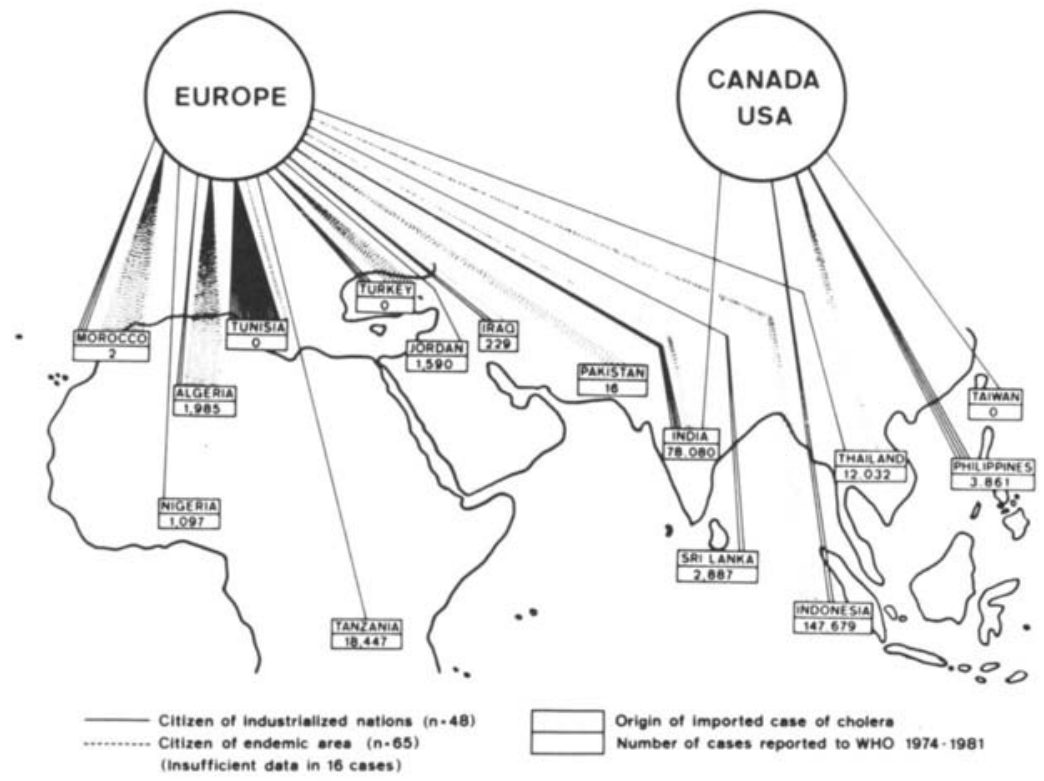


The similarity in chronology and symptomatology of diarrhea in travelers to all destinations, including North America, does not suggest important differences in the causative agents. (4) In contrast, quantitative variations in the doses of infecting pathogens may explain why certain destinations are associated with a high incidence of travelers' diarrhea, a high proportion of cases with early onset, and an elevated proportion of cases with concomitant symptoms and prolonged duration of illness. (5) Self-restricted changes in eating habits, which may also be termed nutritional prophylaxis, would be largely effective if appropriately implemented. It remains an open question, however, as to how and to what extent tourists can, realistically, be educated not to succumb to gastronomic temptation. (6) Travelers often erroneously believe that immunization against typhoid and cholera will protect them against travelers' diarrhea. The former two diseases are actually rare and do not present a significant threat to travelers.

\section{References}

1. Steffen R, van der Linde F, Gyr K, Schär M. Epidemiology of diarrhea in travelers. JAMA 1983;249:1176-80

2. Merson MH, Morris GK, Sack DA, Wells JG, Felley JC, Sack RB, Creech WB, Kapikian AZ, Gangarosa EJ. Travelers' diarrhea in Mexico: a prospective study of physicians and family members attending a congress. $N$ Engl $J$ Med 1976;294:1299-305

3. Sack DA, Kaminsky DC, Sack RB, Itotia JN, Arthur RR,

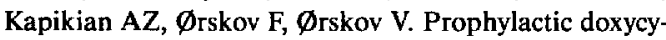
cline for travelers' diarrhea: results of a prospective doubleblind study of Peace Corps volunteers in Kenya. N Engl J Med 1978;298:758-63

4. Salvato JA. Guide d'hygiène dans les établissements touristiques. Geneva: World Health Organization, 1977
5. DuPont HL. Modern views on travellers' diarrhoea (emporiatric enteritis). Trans R Soc Trop Med Hyg 1981;75:137-40

6. Kean BH, Waters SR. The diarrhea of travelers. N Engl J Med 1959;216:71-4

7. Kozicki M, Steffen R, Schär M. "Boil it, cook it, peel it, or forget it": does this rule prevent travellers' diarrhoea? Int J Epidemiol 1985;14:169-72

8. Steffen R. Epidemiology of travellers' diarrhoea. Scand J Gastroenterol 1983;18(Suppl 84):5-17

9. Steffen $R$, van der Linde $F$. Intercontinental travel and its effect on preexisting illnesses. Aviat Space Environ Med 1981;52:57-8

10. Blaser MJ. Environmental interventions for the prevention of travelers' diarrhea. Rev Infect Dis 1986;8(Suppl 2): $\$ 142-50$

11. Steffen R, Rickenbach M, Jungbluth R, Schär M. "Incidence" of relevant imported diseases after short journeys to developing countries [abstract]. In: Proceedings of the 11th International Congress for Tropical Medicine and Malaria, Calgary, Alberta: International Congress for Tropical Medicine and Malaria, 1984:147

12. Steffen R, Schär G, Mosimann J. Salmonella and shigella infections in Switzerland, with special reference to typhoid vaccination for travellers. Scand J Infect Dis 1981;13:121-7

13. Steffen R. Typhoid vaccine, for whom? [letter] Lancet 1982;1:615-6

14. Taylor DN, Pollard RA, Blake PA. Typhoid in the United States and the risk to the international traveler. J Infect Dis 1983;148:599-602

15. PHLS Communicable Disease Surveillance Centre and the Communicable Diseases (Scotland) Unit. Communicable Disease Report, July to September 1983. Community Med 1984;6:72-5

15a. Wüthrich RP, Somaini B, Steffen R, Hirschel B. Typhusepidemiologie in der Schweiz 1980-1983. Schweiz Med Wochenschr 115:1714-20

16. Snyder JD, Blake PA. Is cholera a problem for U.S. travelers? JAMA 1982;247:2268-9

17. Morger H, Steffen R, Schär M. Epidemiology of cholera in travellers, and conclusions for vaccination recommendations. Br Med J [Clin Res] 1983;286:184-6 